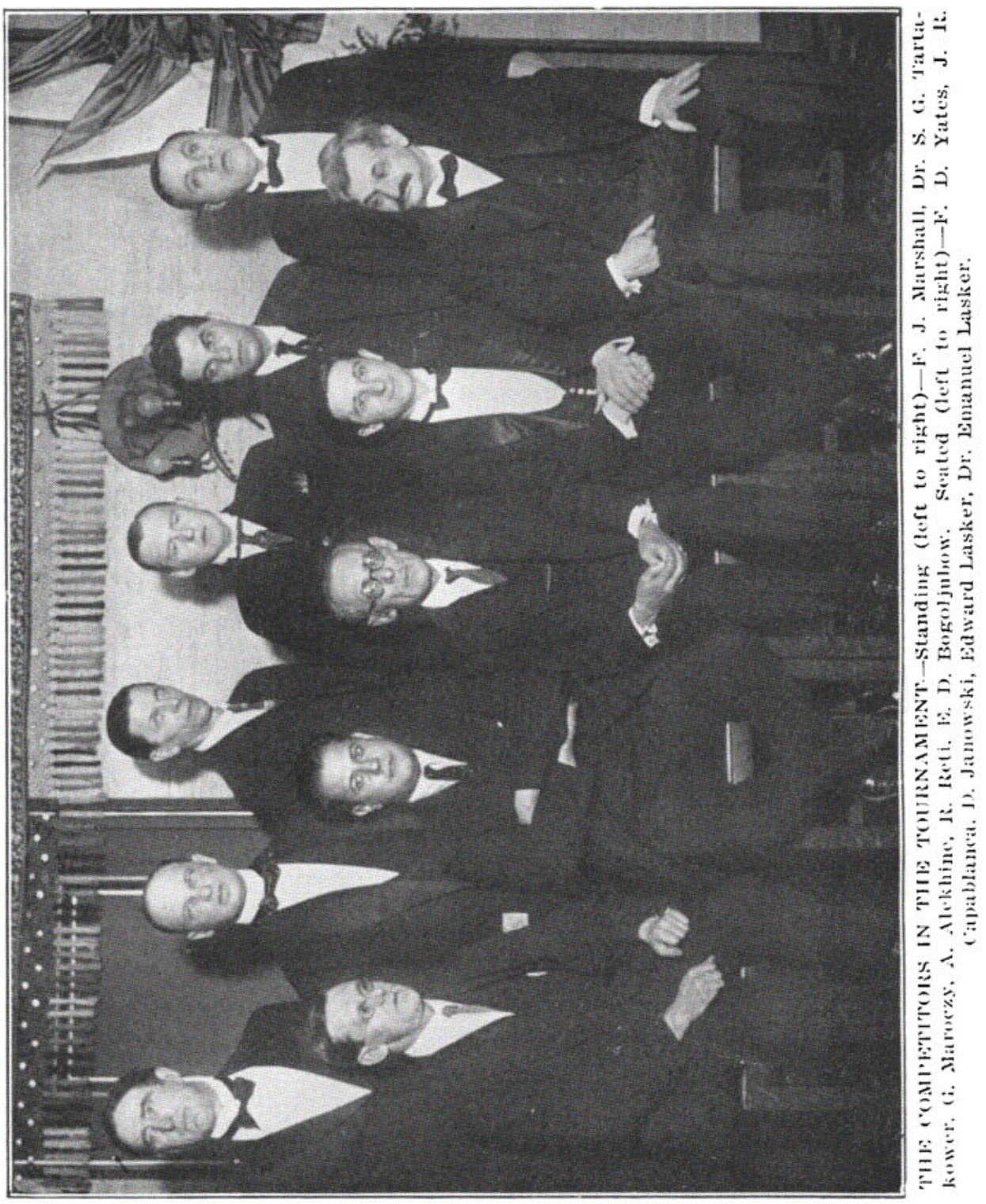




\title{
The Book of the
}

New York International

Chess Tournament

1924

Containing the Authorized Account of the 110 Games Played March-April, 1924

With Original Annotations by ALEXANDER ALEKHINE

\author{
Edited by \\ HERMANN HELMS
}

With Fifteen Photographs

Copyright

United States of America:

THE AMERICAN CHESS

BULLETIN,

150 Nassau Street, New York.

ENGLAND:

PRINTING CRAFT, LTD.

34 Red Lion Square, London, W. C. 1. 


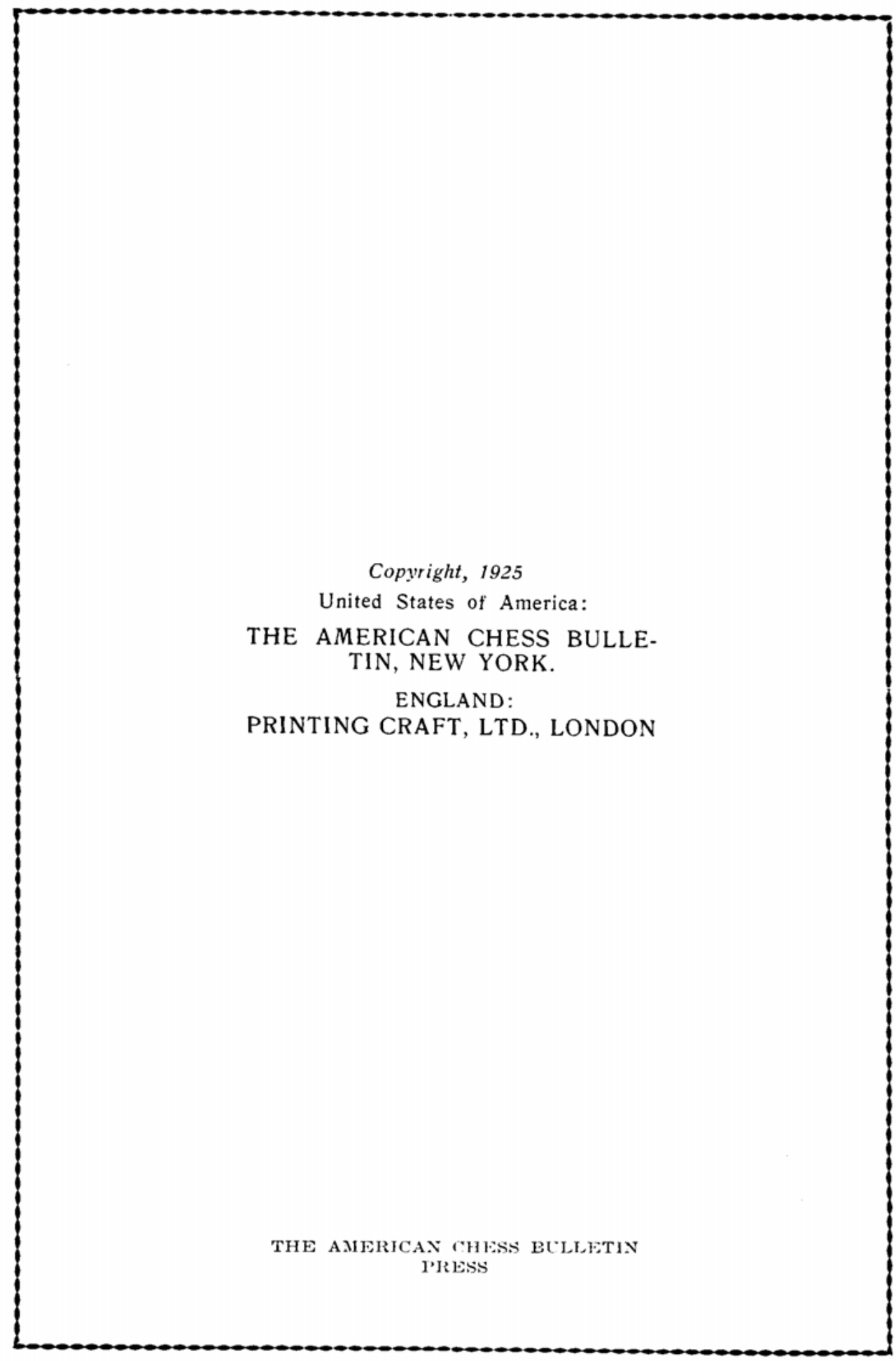

